\title{
A narrative review of early surgery versus conventional treatment for infective endocarditis: do we have an answer?
}

\author{
Umberto Benedetto $^{1}$, Cristiano Spadaccio ${ }^{2,3}$, Federico Gentile $^{4},{\text { Marc R. } \text { Moon }^{5} \text {, Francesco Nappi }}^{6}$ \\ ${ }^{1}$ Department of Cardiothoracic Surgery, Bristol Heart Institute, University of Bristol, Bristol, UK; ${ }^{2}$ Department of Cardiac Surgery, Golden Jubilee \\ National Hospital, Glasgow, UK; ${ }^{3}$ Institute of Cardiovascular and Medical Sciences, University of Glasgow, UK; ${ }^{4}$ Cardiovascular Disease Diagnostic \\ Medical Center, Naples, Italy; ${ }^{5}$ Department of Cardiac Thoracic Surgery, Washington University School of Medicine, Saint Louis, MO, USA; \\ ${ }^{6}$ Department of Cardiac Surgery, Centre Cardiologique du Nord de Saint-Denis, Paris, France \\ Contributions: (I) Conception and design: U Benedetto, C Spadaccio, F Nappi; (II) Administrative support: None; (III) Provision of study materials \\ or patients: None; (IV) Collection and assembly of data: F Nappi; (V) Data analysis and interpretation: U Benedetto, C Spadaccio, F Nappi; (VI) \\ Manuscript writing: All authors; (VII) Final approval of manuscript: All authors. \\ Correspondence to: Francesco Nappi, MD. Department of Cardiac Surgery, Centre Cardiologique du Nord, 36 Rue des Moulins Gémeaux, 93200 \\ Saint-Denis, Paris, France. Email: francesconappi2@gmail.com.
}

\begin{abstract}
The most appropriate strategy and timing for surgery in infective endocarditis (IE) remains an argument of debate. Despite some authors promote the adoption of an early surgical approach (within 48 hours) to limit mortality and complications, no robust randomized trials are available on this argument and the evidence on this subject remain at the "expert opinion" level. Additionally, the different messages promulgated by the American and European guidelines contributed to fuel confusion regarding the relative priority of the surgical over medical therapy in IE. The European Society of Cardiology (ESC) guidelines individuates three level of urgency: emergency surgery, to be performed within 24 hours; urgent surgery, recommended within a few days; elective surgery to be performed after 1-2 weeks of antibiotic therapy. Urgent surgery is recommended for most cases of IE. In the American Heart Association (AHA)'s guidelines define early surgery as "during the initial hospitalization and before completion of a full course of antibiotics." Some of the available evidences showed that are no proven benefits in delaying surgery if a definite diagnosis of IE has been established. However, this argument is controversial across the literature and several factors including the center specific experience can play a role in decision-making. In this review the latest evidences on IE clinical and surgical characteristics along with the current studies on the adoption of an early surgical approach are analyzed to clarify whether enough evidence is available to inform an update of the guidelines.
\end{abstract}

Keywords: Infective endocarditis (IE); guidelines; treatment; management

Submitted May 11, 2020. Accepted for publication Jul 19, 2020.

doi: $10.21037 /$ atm-20-3880

View this article at: http://dx.doi.org/10.21037/atm-20-3880

\section{Introduction}

Despite the progress achieved in recent years for the treatment of infectious endocarditis in both the medical and surgical fields, this clinical-pathological entity remains a serious disease carrying a significant risk of death and morbidity (1-4). The use of surgery has gained momentum in the treatment of infectious endocarditis and it is expanding. However, current guidelines are cautious in supporting broad application of surgery in complicated left-sided infectious endocarditis $(2,5,6)$. Although early surgery is highly recommended in patients with infective endocarditis (IE) who present with signs of congestive heart failure (3-6), the indications for surgery to prevent systemic embolism remain undefined (7-9). The main concern is for patients with large vegetation and a high risk of embolism $(4,10)$. In these patients' early surgery with complete excision of infected tissue and valve repair have 
been achieved in high-volume centers with low mortality suggesting the benefit of early surgical management $(1,4-6,11)$. However, concerns remain regarding the technical challenge of performing surgery in the presence of active infection and inflammatory response $(1,12)$.

The 2014 American College of Cardiology-American Heart Association (ACC-AHA) guidelines (13) recommend the use of early surgery as class IIa indication only in patients who have recurrent emboli and persistent vegetation. Instead, the guidelines of the European Society of Cardiology (ESC) (6) recommend the use of early surgery as class IIb indication in patients who have isolated and very large vegetations ( $>15 \mathrm{~mm}$ in diameter). The nonunivocal recommendation from the two Society guidelines and the lack of randomized studies related to the presence of ethical, logistical, and financial constraints, impede to clarify the best indications for surgery and its timing (6).

The best timing for surgery is even more important in patients with prosthetic valve endocarditis (PVE), which present in $3 \%$ to $6 \%$ of the patients within 5 years of surgery and is associated with significant morbidity and mortality (14-17). Surgical debridement and valve replacement are recommended by consensus guidelines $(6,14)$ in patients with IE who experience complications such as valve dysfunction, dehiscence, heart failure, cardiac abscess, or persistent bacteremia. However, these guidelines rely largely on expert opinion and limited observational data (18). There are several studies that have compared survival between patients undergoing surgery and medical therapy for PVE but they have reported conflicting results $(15,18-25)$. Furthermore, their retrospective nature, low sample size and risk for treatment allocation bias profoundly limit the power of these studies.

The only randomized evidence comparing the use of early surgery to medical treatment enrolled only a small number of patients with native valve endocarditis due to the streptococcal pathogen (26). No randomized studies on PVE are currently available.

The objective of this review is to evaluate whether an answer can be given on the question regarding the best strategy to be adopted in the early treatment of IE.

We present the following article in accordance with the Narrative Review reporting checklist (available at http:// dx.doi.org/10.21037/atm-20-3880).

\section{Methods}

A search of the PubMed database using the terms "endocarditis", "left side endocarditis ", "right side endocarditis", "aortic valve endocarditis", "mitral valve endocarditis", "tricuspid valve endocarditis", "heart valve prosthesis", "allograft", "autograft", "cardiac valve surgery", "early surgery", "delayed surgery", was coordinated. Qualified abstracts were independently reviewed by two investigators and the related articles were evaluated. References for all selected studies were cross checked. Data from randomized controlled trials (RCT), unmatched observational series, observational series corresponding to propensity, meta-analysis, registries, and expert opinion were included.

\section{Clinical evidence}

\section{Patient presentation}

Patients with sepsis of unknown origin or fever in the presence of risk factors should always trigger the suspicion of IE. They should have a careful assessment of symptoms and should undergo a clinical and microbiological investigation followed by transthoracic echocardiography to assess the mechanism and severity of heart valve infection, as well as left ventricular size and function. The manifestations of sepsis can fluctuate from general malaise to shock because they are influenced both by the virulence of the pathogen and by the host's immune response $(27,28)$. Usually Gram-positive Cocci of the staphylococcus, streptococcus and enterococcus species are responsible for $80-90 \%$ of infectious endocarditis. S aureus is the most frequently isolated pathogen in infectious endocarditis in high-income countries with a reported percentage of $30 \%$ of cases $(29,30)$. In particular, a microbiological diagnosis of $\mathrm{S}$ aureus bacteraemia is associated with infectious endocarditis in $25-30 \%$ of cases and all patients must be received echocardiography $(31,32)$.

Patients with IE who present in a critical phase should be judiciously evaluated for risk of embolism and hemodynamic deterioration towards heart failure. Risk factors as underlying hemodialysis or addiction to the intravenous drug should be considered (33). The infection can be localized on the native and prosthetic valves, and patients might be asymptomatic without clinical cardiovascular deterioration for few days after infection (Figure 1).

\section{Hemodynamic decompensation and beart failure}

The most common indication to perform early operation 


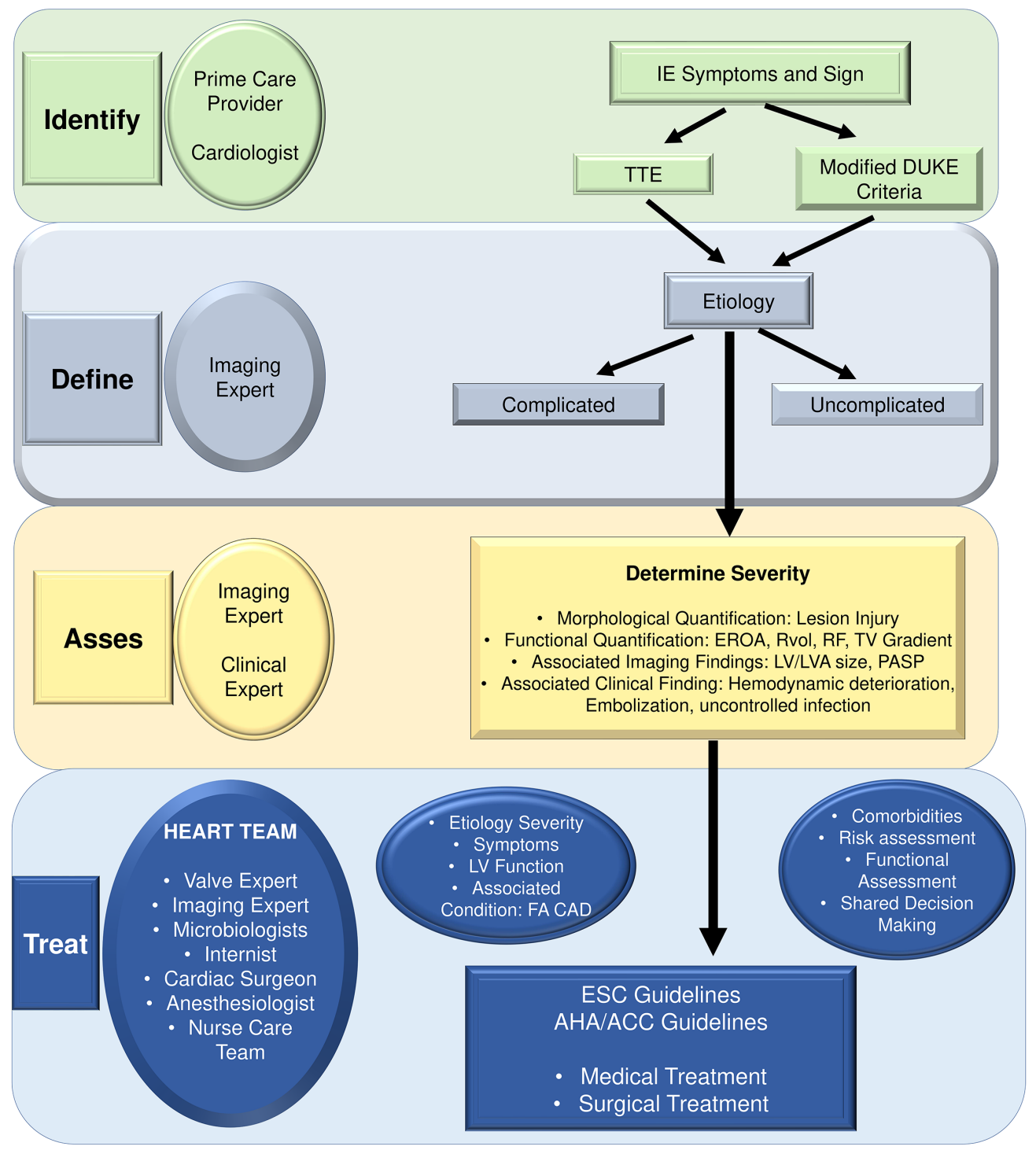

Figure 1 Pathway for Management of IE. ACC/AHA, American College of Cardiology/American Heart association; CAD, coronary artery disease; EROA, effective regurgitant orifice area; ESC, European Society of Cardiologists; FA, atrial fibrillation; IE, infective endocarditis; LV, left ventricle; LA, left atrium; PASP, pulmonary artery systolic pressure; TTE , transthoracic echocardiography; RF, regurgitant fraction; Rvol, regurgitant volume.

in patients with IE is the development of heart failure. Increasing severity of valve regurgitation, even among asymptomatic patients, imposes a volume load on the left ventricle, which, if sustained over time, results in ventricular dilatation, hypertrophy, neurohormonal activation, and heart failure. In addition, in presence of a mitral valve endocarditis elevation in the mean left atrial pressure leads to left atrial enlargement, atrial fibrillation, pulmonary congestion, and pulmonary hypertension. Valve obstruction is another factor determining hemodynamic instability and heart failure. Evidence from numerous cohort studies revealed that the results were nefarious in patients who had not received emergency surgery because of the progression to pulmonary edema or cardiogenic shock (4,34-36). The presence of a large vegetation that compromises the functionality of the entire valve-rarely only a single leaflet is involved-can have a faster deterioration with progression of hemodynamic instability. These patients have valves 


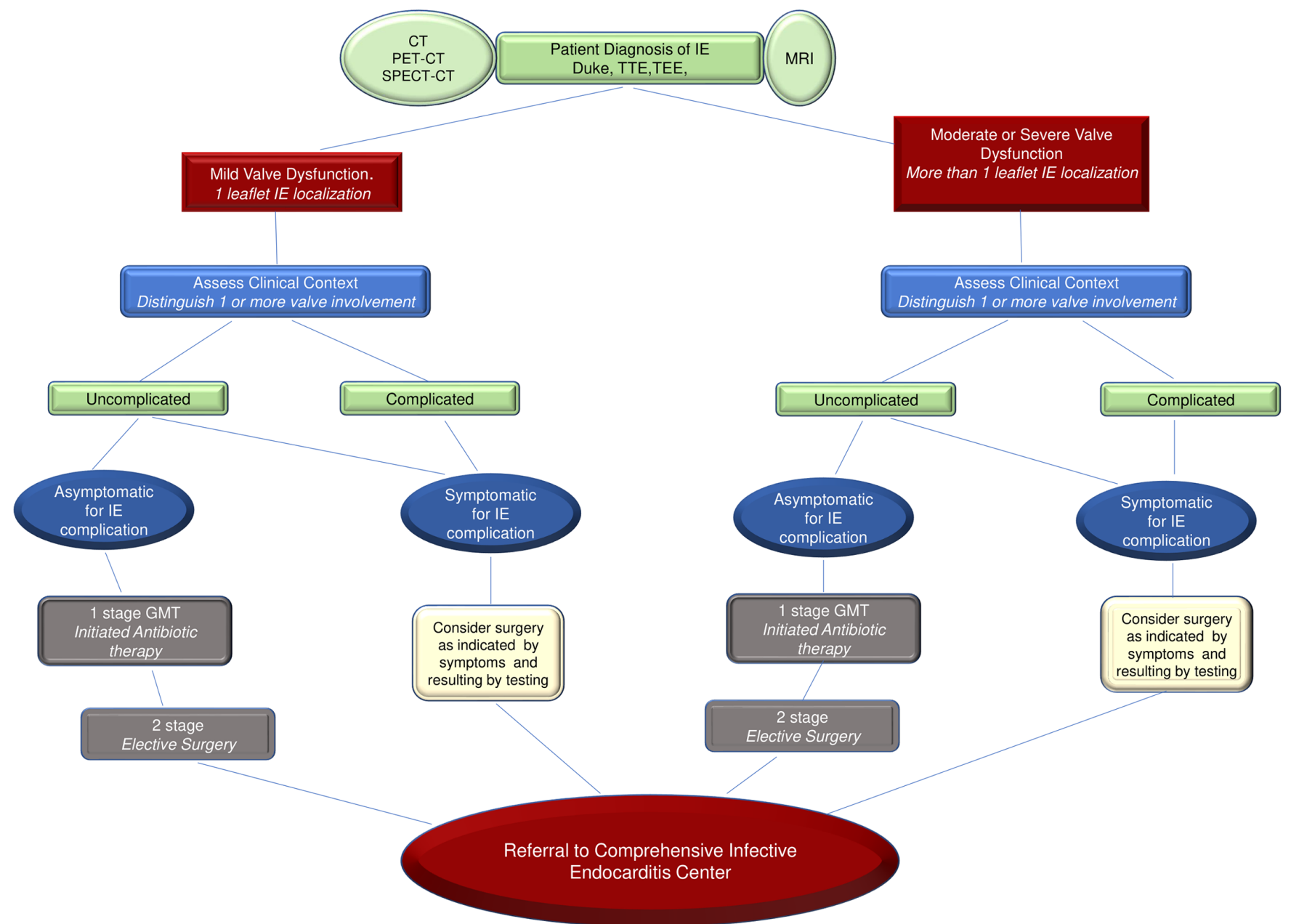

Figure 2 Clinical Algorithm for the Management of IE. CT, computed tomography; GDMT, guide direct medical therapy; MRI, magnetic; PET/CT, positron emission; TEE, transoesophageal echocardiography TTE, transthoracic echocardiography; SPECT, single-photon emission computed tomography.

seriously affected by infection with a cauliflower-like lesion $(4,37)$. In patients with limited degree of valve regurgitation valve regurgitation surgery can be deferred surgery after a period of stabilization with antibiotic therapy, but there are no randomized controlled clinical trials that satisfactorily guide clinical practice in this area $(37,38)$ (Figure 2).

\section{Etiology of Infection}

Coagulase negative staphylococci (e.g., staphylococcus epidermidis, Staphylococcus lugdunensis and Staphylococcus capitis) are omnipresent cutaneous commensals that are implicated in complicated infectious endocarditis. They can colonize native heart valves and are the most common pathogens isolated in early PVE $(19,21,39)$. It is not uncommon for coagulase negative staphylococci to cause hospital-acquired native valve endocarditis (40). In general, three blood culture series detect the presence of these pathogens in $96-98 \%$ of patients with bacteremia who have not yet started treatment with antibiotics $(41,42)$. Blood culture does not need to be done at the febrile peak because the presence of the pathogen in the blood is not related to the extent of the fever. It is possible that patients in a compromised clinical condition have no pathogen growth from blood cultures delaying diagnosis (4). This situation is reported in up to $10 \%$ of cases and it is linked: (I) to the early administration of antibiotics before blood cultures; (II) to the sustained 
infection by slow-growing pathogens or fungi and (III) to particular conditions in which an alternative diagnosis of non-bacterial thrombotic endocarditis is can be made as in patients with advanced cancer (43).

Infection related due to Viridans streptococci vehicle by oro-pharyngeal transmission remains more common in low-income countries (44). Serial blood cultures can lead to the discovery of Streptococcus mutans, Streptococcus salivarius, Streptococcus anginosus, Streptococcus mitis and Streptococcus sanguinis. Of particular interest is the role played by group D streptococci (e.g., Gallolyticus Streptococcus, Streptococcus bovis) that are involved in the IE in patients with a coexisting colon tumor, which provides the portal circulation as a route of entry. The pathogens belonging to the group of Enterococci represent $10 \%$ of the overall cases $(29,30)$.

Other forms of endocarditis are related to zoonotic infection as Coxiella burnetii, Brucella (cattle), Bartonella benselae (from cats) and Chlamydia psittaci (as parrots, pigeons).

Infections caused by Gram-negative bacteria (e.g., Acinetobacter spp, Pseudomonas aeruginosa) and Legionella spp, Mycoplasma spp and Tropheryma whippelii can be of particular concern (45). Furthermore, fungal endocarditis, usually caused by Candida or Aspergillus, are very aggressive and often fatal because it occurs in the immunosuppressed patient or after cardiac surgery, mainly in the prosthetic valve recipients (46).

A causative pathogen for IE can be identified in about two thirds of patients by additional microbiological tests (47). If the patient has negative cultures at 5 days, serological tests for Coxiella and bartonella are indicated and if these is also negative, the next step should involve testing for brucella, Mycoplasma, Legionella, and chlamydia (48). In the presence of an unrecognized infection, prolonged blood culture after 7 days does not provide further useful yields, even for the HACEK bacteria, which are typically slow-growing $(48,49)$. After surgery the possibility of having samples the valve, can help in the microbiological diagnosis through the use of complementary molecular techniques as polymerase chain reaction for pathogen DNA (PCR) (50-52). These techniques are particularly useful in patients that received antibiotics, as bacterial DNA often persists even for noncultivable pathogens such as Twhipplei $(51,53)$.

However, PCR carries the risk of a false positive result due to contamination of the sample. Clearly in this case PCR should not be used to guide the duration of therapy. New techniques combining PCR and mass spectrometry promise direct characterization of bacteria in peripheral blood or valvular tissue (51).

During the IE a very important factor is the host immune response where the macrophages play a key role (54). In the most fragile patients and in the presence of very aggressive pathogens infection can be spread beyond the valve annulus. The use of echocardiography plays a key role in the diagnosis and identification of anatomopathological complications resulting from the progression and expansion of the infection. Extension of the lesion inducing the formation of abscess, pseudoaneurysm, fistula, or atrioventricular block define a complex IE. Although transthoracic echocardiography (TTE) is sensitive (75\%) and specific (more than $90 \%$ ) for detection of a vegetation, transoesophageal echocardiography (TOE) is required for detection of complicated extensive lesion because it offers a sensitivity of more than $90 \%$ (55). The TOE colour doppler analysis can reveal a pseudoaneurysm, i.e. a perivalvular cavity that communicates with the cardiovascular lumen. Conversely, an abscess is a thickened, pus-filled perivalvular cavity that has no such communication. A progressive perivalvular infection can evolve into the formation of fistula whose pathoanatomical feature is usually an aortocavitary aspect. The onset of this complication is burdened by a mortality rate greater than $40 \%$ even with surgery (56). For patients with persistent or relapsing infection or infection caused by aggressive or antibiotic-resistant microorganisms (e.g., lugdunensis, pseudomonas, fungi) there is an indication for emergency surgery (57) (Figure 2).

\section{Risk of embolism}

The risk of embolism with devastating complication occurs for a percentage of $25-50 \%$ of patients with IE (10). In the presence of left side endocarditis, the onset of a stroke is more common than infarction at level of the kidneys, spleen, limbs, mesenteric and coronary arteries. Furthermore, the localization of septic emboli in the context of the vascular structure can provoke a secondary infection related to the colonization of the "metastatic" vegetations. The inflammatory process that arises in the vascular wall is the cause of formation of a mycotic aneurysm. This lesion develops more frequently in the cerebral vessels and are visible on brain imaging in 3-5\% of patients with IE, although in most cases they can remain clinically silent (10,58-60). The IE that are localized in right-sided of the heart are potentially at risk to determine lung embolism, or systemic embolism in patients 
presenting a patent foramen ovale. In a large percentage of patients emboli give a clinical manifestation in the first 2 weeks after the diagnosis and the risk decreases rapidly after the initiation of therapy with antibiotics $(61,62)$. Vilacosta et al. (61) evaluated the risk of systemic embolization in 217 patients with left-sided IE who had initiated an adequate antibiotic treatment. In patients undergoing antibiotic therapy reduced rate embolic events was observed $[12.9 \%$ vs. $87.1 \%$; relative risk of new embolization (RR) $1.73 ; 95 \% \mathrm{CI}, 1.2$ to $2.93 ; \mathrm{P}=0.05]$. The majority of emboli (52\%) affected the central nervous system, and $65 \%$ of the embolic events occurred during the first two weeks after initiation of antibiotic treatment. The authors showed that there was an increased risk of embolization parallel to vegetation size (RR 3.77, 95\% CI from 0.97 to $12.57 ; \mathrm{P}=0.07)$. In addition, both the presence of large $(>10 \mathrm{~mm})$ vegetation caused by staphylococcal Aureus pathogens $(\mathrm{P}=0.04)$ and the location on the mitral valve $(\mathrm{P}=0.03)$ had a higher incidence of embolism (61). In another report, 1,437 patients with IE were studied to determine the relationship between the initiation of antimicrobial therapy and the temporal incidence of stroke. During the study, the approximate incidence of stroke in patients receiving appropriate antimicrobial therapy was $4.82 / 1,000$ patient days in the first week of therapy with a reduction to $1.71 / 1,000$ patient days in the second week. Note that after one week of antimicrobial therapy, only $3.1 \%$ of the cohort had a stroke and reduced stroke rates was evident regardless of the type of valve or pathogen involved (62).

In patients who have experienced a stroke, surgery should not be postponed in cases with no coma and cerebral hemorrhage (class IIa, level B). In patients with neurological diagnosis of minor brain events, such as transient ischemic attack or silent cerebral embolism, the criterion is to recommend surgery without delay (class 1, level B) (5). Conversely, in patients who have experienced devastating neurological events such as intracranial hemorrhage and brain localization of septic emboli with hemorrhagic evolution intervention should be delayed for at least 1 month. In this category of patients it is recommended to perform CT scans or MRI perfusion scan to evaluate the progression of the lesion according to the guidelines (class IIa, level B) (5). Okita et al. specific investigations revealed that early surgery ( $<7$ days) demonstrated safety and efficacy in patients included in class I and IIa level B without preoperative haemorrhagic stroke (63). CT scans repeated immediately before surgery can rule out hemorrhagic evolution of cerebral infarction or the development of mycotic aneurysm (64) (Figure 2).

\section{Clinical considerations}

Over the past 20 years 7 RCT were published on antibiotic treatment (65-70), but only one RCT (26) investigated the comparison between medical therapy and early surgery within 48 hours. Thus, conclusive evidence to indicate which of these interventions is superior is missing.

In patients with IE the use of early surgery performed within 48 after diagnosis revealed a decrease in the rate of death from any causes as well as a reduction of the risk of systemic embolism $(4,5,26,71,72)$. The concern related to the use of early surgery may be related to an increase in operative mortality and an increased risk of recurrence of IE. However, in patients who underwent emergency surgery we observed improvements in clinical outcomes were achieved without an increase in operative mortality or recurrence of infectious endocarditis (4,5,71-73). These results were comparable to those by Kang et al. (26). The mortality rate is related to the extension of infectious lesion and the etiology and the localization vegetation on the mitral valve leaflet $(4,59)$. Particular attention should be given to the risk of embolization which has been reported to be particularly high in the first week before diagnosis (7) and affecting the central nervous system in up to $65 \%(1,2,74)$.

Nonetheless, several propensity matched analyses showed contradictive results in terms of surgery morbidity and mortality $(26,75,76)$. This might be related to the weight of embolic stroke and heart failure as determinants of long-term mortality. However, treatment allocation bias, underpowering and survivor bias affecting retrospective studies surely have played a role $(26,75,77)$.

In the sole RCT (26) the rate of embolism in patients who received early surgery was markedly reduced as compared to those who had conventional treatment. The rate of embolism in the medical treatment arm was similar to that reported in other prospective multicenter study (10) or RCT (68).

We have reported that with a careful selection of patients could result in low in-hospital mortality and 6-months mortality $(4,5,71,72)$. Poor prognostic factors, such as moderate to severe congestive heart failure, altered mental status and staphylococcal infection lead to increased mortality, substantially comparable to that of other studies (26,78-83). In our experience, patients with vegetations $>15 \mathrm{~mm}$ at high risk of mobility and located on the mitral 
valve, derive a considerable benefit from emergency surgical treatment, as confirmed elsewhere $(4,5,37,38,71,72)$.

Emergency surgical treatment within 48 hours can be offered to patients who experienced an infection with severe anatomic-pathological injuries with development of abscess, extracardiac fistula or aortic root involvement. In this case the risk of mortality is higher considering the technical demand and the preoperative patient's conditions.

In these patients an extensive and radical surgery is necessary and homografts, conventional mechanical valves or xenografts are used in similar complex endocarditis. In a study reported by Harvard group (79) the abscess formation had an incidence of $43.09 \%(n=131)$, which is higher than the mean frequency $(25-30 \%)$ reported by other international studies, indicating the severity of the disease treated in this cohort. In any case out of 131 patients with abscess formation $40.5 \%$ received a mechanical valve and while $29.5 \%$ were treated using xenograft. Selection of the type of graft to be used should be driven by the resistance to infection, as re-do surgery in case of reinfection is particularly challenging and burdened by augmented risk. In particular, reinfection of synthetic prostheses or prosthetic materials is even more daunting and technically demanding than in case of re-endocarditis on a previous homograft. In this context, evidences on safety and durability of homograft surgery has been widely reported. Already in 2001, Moon et al. (84) revealed a reinfection rate of $2 \%$ at 10 years with the majority of infection relapse following aortic valve endocarditis surgery and occurring within the first year. More recently Flameng et al. (85) showed a low recurrence of endocarditis in patients who received a homograft to treat complex IE. Excellent results are reported in the large series of Arabkhani et al. (86) with a rate of intraoperative mortality of $5.5 \%$ and durability up to 27 years.

Although some reports, as the current from Harvard (79), praised the long-term outcomes of mechanical valves, it cannot be neglected that these prostheses are bond to a life-long anticoagulation which carries significant risks. Additionally, the population normally afflicted by endocarditis is relatively young and willing to conduct an active life and oral anticoagulation means a significant impairment in patient's quality of life. Also, in case of female patients, possibility of pregnancy is excluded. Moreover, if we take into consideration the final objective of endocarditis treatment, there is a significant lower infection recurrence using homografts $(87,88)$ even in the context of previous prosthetic valve (89).

We reported the use of cryopreserved homograft for
AVR in 210 patients (72) and one half of the patients had endocarditis, $21 \%$ of these had an abscess formation. In our series the use of a cryopreserved aortic homograft was associated with no early reinfection and only 4 late relapses of endocarditis. In presence of extensive infection, in young patients with complex aorto-mitral endocarditis or aortic root involvement we used a living pulmonary autograft (90-95) or a double homograft valve replacement $(4,5,71)$. In our experimental studies from a mechanical point of view, the use of a PA has shown efficacy compared to the use of dacron $(96,97)$.

We believe that in case of extensive infection performing a quicker operation using a prosthetic valve with or without a dacron graft provides a very unstable situation with high potential for infection recurrence (72). Decision on surgery is always deriving from a balance between the risk of the procedure and the benefit achievable. Therefore, considering the significant risk during endocarditis surgery and the even higher risk represented by a redo-operation for re-infection, we believe that the option to undergo a minimal operation with known potential for re-infection should be discouraged (Figure 3).

\section{Conclusions}

The indication for early surgery in IE has not yet been appropriately defined and it differs significantly between the European (5) and US guidelines (13) fueling the confusion regarding the relative priority of surgical or medical management. The ESC guidelines (5) individuates three moments for the surgical indication. Emergency surgery which is performed within 24 hours, urgent surgery which is recommended within a few days and elective surgery which is performed after 1-2 weeks of antibiotic therapy. Urgent surgery is recommended for most cases of IE. Instead, the AHA's guidelines (13) define early surgery as "during the initial hospitalization and before completion of a full course of antibiotics." We believe that in the presence of a clear diagnosis of IE and when an indication for surgery has been established, there are no proven benefits in delaying surgery $(4,26)$. The choice to perform an intervention for IE in the early hours or with a delay of 48 hours depends on the way the heart team works in the shared decision-making process (4). There is evidence that has shown very low mortality in centers of excellence with high level experience in the management of complex patients and a RCT (26) has supported the role of early surgery. However, further evidences are needed to inform guidelines on the surgical 


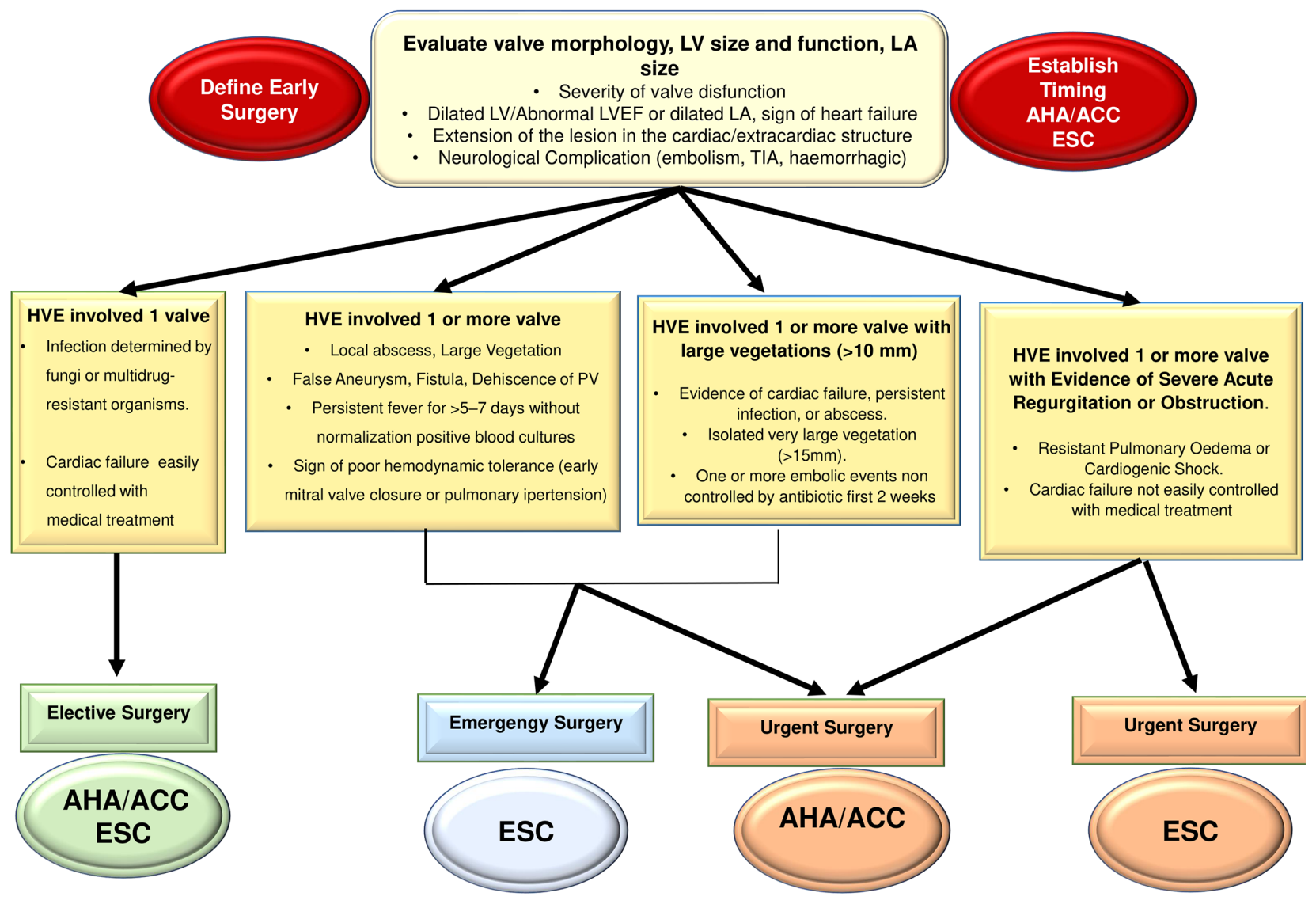

Figure 3 Decision Tree for Distinguishing Early Surgery in HVE. LV, left ventricle; LA, left atrium; ACC/AHA, American College of Cardiology/American Heart association; ESC, European Society of Cardiologists; HVE, heart valve endocarditis; LVEF, left ventricular ejection fraction; TIA, transient Ischemic attack.

management of IE (Figure 3).

\section{Acknowledgments}

Funding: None.

\section{Footnote}

Provenance and Peer Review: This article was commissioned by the Guest Editors (Drs. Francesco Nappi, Christos Mihos, and Cristiano Spadaccio) for the series "Infective Endocarditis in the 21st Century" published in Annals of Translational Medicine. The article was sent for external peer review organized by the Guest Editors and the editorial office.

Reporting Checklist: The authors have completed the
Narrative Review reporting checklist. Available at http:// dx.doi.org/10.21037/atm-20-3880

Conflicts of Interest: All authors have completed the ICMJE uniform disclosure form (available at http:// dx.doi.org/10.21037/atm-20-3880). The series "Infective Endocarditis in the 21 st Century" was commissioned by the editorial office without any funding or sponsorship. FN served as the unpaid Guest Editor of the series and serves as an unpaid editorial board member of Annals of Translational Medicine from Feb 2019 to Jan 2021. CS served as the unpaid Guest Editor of the series. The other authors have no other conflicts of interest to declare.

Ethical Statement: The authors are accountable for all aspects of the work in ensuring that questions related to the accuracy or integrity of any part of the work are 
appropriately investigated and resolved.

Open Access Statement: This is an Open Access article distributed in accordance with the Creative Commons Attribution-NonCommercial-NoDerivs 4.0 International License (CC BY-NC-ND 4.0), which permits the noncommercial replication and distribution of the article with the strict proviso that no changes or edits are made and the original work is properly cited (including links to both the formal publication through the relevant DOI and the license). See: https://creativecommons.org/licenses/by-nc-nd/4.0/.

\section{References}

1. Mylonakis E, Calderwood SB. Infective endocarditis in adults. N Engl J Med 2001;345:1318-30.

2. Baddour LM, Wilson WR, Bayer AS, et al. Infective endocarditis: diagnosis, antimicrobial therapy, and management or complications: a statement for healthcare professionals from the Committee on Rheumatic Fever, Endocarditis, and Kawasaki Disease, Council on Cardiovascular Disease in the Young, and the Councils on Clinical Cardiology, Stroke, and Cardiovascular Surgery and Anesthesia, American Heart Association: endorsed by the Infectious Diseases Society of America. Circulation 2005;111:e394-434.

3. Nappi F, Spadaccio C, Dreyfus J, et al. Mitral endocarditis: A new management framework. J Thorac Cardiovasc Surg 2018;156:1486-95.e4.

4. Nappi F, Spadaccio C, Acar C. Use of allogeneic tissue to treat infective valvular disease: Has everything been said? J Thorac Cardiovasc Surg 2017;153:824-8.

5. Habib G, Hoen B, Tornos P, et al. Guidelines on the prevention, diagnosis, and treatment of infective endocarditis (new version 2009): the Task Force on the Prevention, Diagnosis, and Treatment of Infective Endocarditis of the European Society of Cardiology (ESC). Eur Heart J 2009;30:2369-413.

6. Prendergast BD, Tornos P. Surgery for infective endocarditis: who and when? Circulation 2010;121:1141-52.

7. Cahill TJ, Baddour LM, Habib G, et al. Challenges in Infective Endocarditis. J Am Coll Cardiol 2017;69:325-44.

8. Cahill TJ, Prendergast BD. Infective endocarditis. Lancet 2016;387:882-93.

9. Moreillon P, Que YA. Infective endocarditis. Lancet 2004;363:139-49.

10. Thuny F, Di Salvo G, Belliard O, et al. Risk of embolism and death in infective endocarditis: prognostic value of echocardiography: a prospective multicenter study. Circulation 2005;112:e175.

11. Tornos P, Iung B, Permanyer-Miralda G, et al. Infective endocarditis in Europe: lessons from the Euro heart survey. Heart 2005;91:571-5.

12. Delahaye F. Is early surgery beneficial in infective endocarditis? A systematic review. Arch Cardiovasc Dis 2011;104:35-44.

13. Nishimura RA, Otto CM, Bonow RO, et al. 2017 AHA/ ACC Focused Update of the 2014 AHA/ACC Guideline for the Management of Patients With Valvular Heart Disease: A Report of the American College of Cardiology/ American Heart Association Task Force on Clinical Practice Guidelines. Circulation 2017;135:e1159-95.

14. Agnihotri AK, McGiffin DC, Galbraith AJ, et al. The prevalence of infective endocarditis after aortic valve replacement. J Thorac Cardiovasc Surg 1995;110:1708-20.

15. Calderwood SB, Swinski LA, Waternaux CM, et al. Risk factors for the development of prosthetic valve endocarditis. Circulation 1985;72:31-7.

16. Arvay A, Lengyel M. Incidence and risk factors of prosthetic valve endocarditis. Eur J Cardiothorac Surg 1988;2:340-6.

17. Wang A, Athan E, Pappas PA, et al. Contemporary clinical profile and outcome of prosthetic valve endocarditis. JAMA 2007;297:1354-61.

18. Attaran S, Chukwuemeka A, Punjabi PP, et al. Do all patients with prosthetic valve endocarditis need surgery? Interact Cardiovasc Thorac Surg 2012;15:1057-61.

19. Alonso-Valle H, Fariñas-Alvarez C, García-Palomo JD, et al. Clinical course and predictors of death in prosthetic valve endocarditis over a 20-year period. J Thorac Cardiovasc Surg 2010;139:887-93.

20. Habib G, Tribouilloy C, Thuny F, et al. Prosthetic valve endocarditis: who needs surgery? A multicentre study of 104 cases. Heart 2005;91:954-9.

21. López J, Revilla A, Vilacosta I, et al. Definition, clinical profile, microbiological spectrum, and prognostic factors of early-onset prosthetic valve. Eur Heart J 2007;28:760-5.

22. Chirouze C, Cabell CH, Fowler VG Jr, et al. International Collaboration on Endocarditis Study Group. Prognostic factors in 61 cases of Staphylococcus aureus prosthetic valve infective endocarditis from the International Collaboration on Endocarditis merged database. Clin Infect Dis 2004;38:1323-7.

23. Tornos P, Almirante B, Olona M, et al. Clinical outcome and long-term prognosis of late prosthetic valve endocarditis: a 20-year experience. Clin Infect Dis 
1997;24:381-6.

24. Truninger K, Attenhofer Jost CH, Seifert B, et al. Long term follow up of prosthetic valve endocarditis: what characteristics identify patients who were treated successfully with antibiotics alone? Heart 1999;82:714-20.

25. Rekik S, Trabelsi I, Maaloul I, et al. Short- and long-term outcomes of surgery for active infective endocarditis: a Tunisian experience. Interact Cardiovasc Thorac Surg 2009;9:241-5.

26. Kang DH, Kim YJ, Kim SH, et al. Early surgery versus conventional treatment for infective endocarditis. N Engl J Med 2012;366:2466-73.

27. Olmos C, Vilacosta I, Fernandez C, et al. Contemporary epidemiology and prognosis of septic shock in infective endocarditis. Eur Heart J 2013;34:1999-2006.

28. Werdan K, Dietz S, Löffler B, et al. Mechanisms of infective endocarditis: pathogen-host interaction and risk states. Nat Rev Cardiol 2014;11:35-50.

29. Murdoch DR, Corey GR, Hoen B, et al. Clinical presentation, etiology, and outcome of infective endocarditis in the 21st century: the International Collaboration on Endocarditis-Prospective Cohort Study. Arch Intern Med 2009;169:463-73.

30. Selton-Suty C, Célard M, Le Moing V, et al, and the AEPEI Study Group. Preeminence of Staphylococcus aureus in infective endocarditis: a 1-year population-based survey. Clin Infect Dis 2012;54:1230-39.

31. Fowler VG Jr, Li J, Corey GR, et al. Role of echocardiography in evaluation of patients with Staphylococcus aureus bacteremia: experience in 103 patients. J Am Coll Cardiol 1997;30:1072-78.

32. Joseph JP, Meddows TR, Webster DP, et al. Prioritizing echocardiography in Staphylococcus aureus bacteraemia. J Antimicrob Chemother 2013;68:444-49.

33. Durante-Mangoni E, Bradley S, Selton-Suty C, et al. Current features of infective endocarditis in elderly patients: results of the International Collaboration on Endocarditis Prospective Cohort Study. Arch Intern Med 2008;168:2095-103.

34. Richardson JV, Karp RB, Kirklin JW, et al. Treatment of infective endocarditis: a 10-year comparative analysis. Circulation 1978;58:589-97.

35. Croft CH, Woodward W, Elliott A, et al. Analysis of surgical versus medical therapy in active complicated native valve infective endocarditis. Am J Cardiol 1983;51:1650-55.

36. Gálvez-Acebal J, Almendro-Delia M, Ruiz J, et al. Study Group for Cardiovascular Infections, part of the
Andalusian Society of Infectious Diseases. Influence of early surgical treatment on the prognosis of left-sided infective endocarditis: a multicenter cohort study. Mayo Clin Proc 2014;89:1397-405.

37. Nappi F, Spadaccio C. Simplest solutions are not always the cleverest: Can we stitch in an infected annulus? Should we rethink the current guidelines? J Thorac Cardiovasc Surg 2017;154:1899-900.

38. Nappi F, Spadaccio C. Keep fumbling around in the dark when it comes to infective endocarditis, or produce new, reliable data to redesign the guidelines? J Thorac Cardiovasc Surg 2018;155:75-6.

39. Becker K, Heilmann C, Peters G. Coagulase-negative staphylococci. Clin Microbiol Rev 2014;27:870-926.

40. Chu VH, Woods CW, Miro JM, et al. Emergence of coagulase-negative staphylococci as a cause of native valve endocarditis. Clin Infect Dis 2008;46:232-42.

41. Lee A, Mirrett S, Reller LB, et al. Detection of bloodstream infections in adults: how many blood cultures are needed? J Clin Microbiol 2007;45:3546-8.

42. Cockerill FR 3rd, Wilson JW, Vetter EA, et al. Optimal testing parameters for blood cultures. Clin Infect Dis 2004;38:1724-30.

43. Asopa S, Patel A, Khan OA, et al. Non-bacterial thrombotic endocarditis. Eur J Cardiothorac Surg 2007;32:696-701.

44. Yew HS, Murdoch DR. Global trends in infective endocarditis epidemiology. Curr Infect Dis Rep 2012;14:367-72.

45. Brouqui P, Raoult D. Endocarditis due to rare and fastidious bacteria. Clin Microbiol Rev 2001;14:177-207.

46. Baddley JW, Benjamin DK Jr, Patel M, et al. Candida infective endocarditis. Eur J Clin Microbiol Infect Dis 2008;27:519-29.

47. Fournier PE, Thuny F, Richet H, et al. Comprehensive diagnostic strategy for blood culture-negative endocarditis: a prospective study of 819 new cases. Clin Infect Dis 2010;51:131-40.

48. Gould FK, Denning DW, Elliott TSJ, et al. Guidelines for the diagnosis and antibiotic treatment of endocarditis in adults: a report of the Working Party of the British Society for Antimicrobial Chemotherapy. J Antimicrob Chemother 2012;67:269-89.

49. Petti CA, Bhally HS, Weinstein MP, et al. Utility of extended blood culture incubation for isolation of Haemophilus, Actinobacillus, Cardiobacterium, Eikenella, and Kingella organisms: a retrospective multicenter evaluation. J Clin Microbiol 2006;44:257-59.

50. Goldenberger D, Künzli A, Vogt P, et al. Molecular 
diagnosis of bacterial endocarditis by broad-range PCR amplification and direct sequencing. J Clin Microbiol 1997;35:2733-9.

51. Vondracek M, Sartipy U, Aufwerber E, et al. $16 \mathrm{~S}$ rDNA sequencing of valve tissue improves microbiological diagnosis in surgically treated patients with infective endocarditis. J Infect 2011;62:472-8.

52. Bosshard PP, Kronenberg A, Zbinden R, et al. Etiologic diagnosis of infective endocarditis by broad-range polymerase chain reaction: a 3-year experience. Clin Infect Dis 2003;37:167-72.

53. Geissdörfer W, Moos V, Moter A, et al. High frequency of Tropheryma whipplei in culture-negative endocarditis. J Clin Microbiol 2012;50:216-22.

54. Brinkman CL, Vergidis P, Uhl JR, et al. PCR-electrospray ionization mass spectrometry for direct detection of pathogens and antimicrobial resistance from heart valves in patients with infective endocarditis. J Clin Microbiol 2013;51:2040-6.

55. Habib G, Badano L, Tribouilloy C, et al. Recommendations for the practice of echocardiography in infective endocarditis. Eur J Echocardiogr 2010;11:202-19.

56. Anguera I, Miro JM, Vilacosta I, et al. Aorto-cavitary fistulous tract formation in infective endocarditis: clinical and echocardiographic features of 76 cases and risk factors for mortality. Eur Heart J 2005;26:288-97

57. Malhotra A, Rayner J, Williams TM, et al. Infective endocarditis: therapeutic options and indications for surgery. Curr Cardiol Rep 2014;16:464-9.

58. Peters PJ, Harrison T, Lennox JL. A dangerous dilemma: management of infectious intracranial aneurysms complicating endocarditis. Lancet Infect Dis 2006;6:742-8.

59. Duval X, Iung B, Klein I, et al. Effect of early cerebral magnetic resonance imaging on clinical decisions in infective endocarditis: a prospective study. Ann Intern Med 2010;152:497-504.

60. Hess A, Klein I, Iung B, et al. Brain MRI findings in neurologically asymptomatic patients with infective endocarditis. AJNR Am J Neuroradiol 2013;34:1579-84.

61. Vilacosta I, Graupner C, San Román JA, et al. Risk of embolization after institution of antibiotic therapy for infective endocarditis. J Am Coll Cardiol 2002;39:1489-95.

62. Dickerman SA, Abrutyn E, Barsic B, et al. The relationship between the initiation of antimicrobial therapy and the incidence of stroke in infective endocarditis: an analysis from the ICE Prospective Cohort Study (ICE-PCS). Am Heart J 2007;154:1086-94.

63. Okita Y, Minakata K, Yasuno S, et al. Optimal timing of surgery for active infective endocarditis with cerebral complications: a Japanese multicentre study. Eur J Cardiothorac Surg 2016;50:374-82.

64. Hui FK, Bain M, Obuchowski NA, et al. Mycotic aneurysm detection rates with cerebral angiography in patients with infective endocarditis. J Neurointerv Surg 2015;7:449-52.

65. Ribera E, Gómez-Jimenez J, Cortes E, et al. Effectiveness of cloxacillin with and without gentamicin in shortterm therapy for right-sided Staphylococcus aureus endocarditis. A randomized, controlled trial. Ann Intern Med 1996;125:969-74.

66. Fowler VG Jr., Boucher HW, Corey GR, et al. Daptomycin versus standard therapy for bacteremia and endocarditis caused by Staphylococcus aureus. N Engl J Med 2006;355:653-65.

67. Heldman AW, Hartert TV, Ray SC, et al. Oral antibiotic treatment of right-sided staphylococcal endocarditis in injection drug users: prospective randomized comparison with parenteral therapy. Am J Med 1996;101:68-76.

68. Chan KL, Dumesnil JG, Cujec B, et al. A randomized trial of aspirin on the risk of embolic events in patients with infective endocarditis. J Am Coll Cardiol 2003;42:775-80.

69. Fortún J, Navas E, Martínez-Beltrán J, et al. Short-course therapy for right-side endocarditis due to Staphylococcus aureus in drug abusers: cloxacillin versus glycopeptides in combination with gentamicin. Clin Infect Dis 2001;33:120-5.

70. Sexton DJ, Tenenbaum MJ, Wilson WR, et al. Ceftriaxone once daily for four weeks compared with ceftriaxone plus gentamicin once daily for two weeks for treatment of endocarditis due to penicillin susceptible streptococci. Endocarditis Treatment Consortium Group. Clin Infect Dis 1998;27:1470-4.

71. Olivito S, Lalande S, Nappi F, et al. Structural deterioration of the cryopreserved mitral homograft valve. J Thorac Cardiovasc Surg 2012;144:313-20.e1.

72. Nappi F, Nenna A, Petitti T, et al. Long-term outcome of cryopreserved allograft for aortic valve replacement. J Thorac Cardiovasc Surg 2018;156:1357-65.e6.

73. Steckelberg JM, Murphy JG, Ballard D, et al. Emboli in infective endocarditis: the prognostic value of echocardiography. Ann Intern Med 1991;114:635-40.

74. Habib G. Management of infective endocarditis. Heart 2006;92:124-30.

75. Vikram HR, Buenconsejo J, Hasbun R, et al. Impact of valve surgery on 6-month mortality in adults with complicated, left-sided native valve endocarditis: a 
propensity analysis. JAMA 2003;290:3207-14.

76. Lalani T, Cabell CH, Benjamin DK, et al. Analysis of the impact of early surgery on in-hospital mortality of native valve endocarditis: use of propensity score and instrumental variable methods to adjust for treatmentselection bias. Circulation 2010;121:1005-13.

77. Thuny F, Beurtheret S, Mancini J, et al. The timing of surgery influences mortality and morbidity in adults with severe complicated infective endocarditis: a propensity analysis. Eur Heart J 2011;32:2027-33.

78. David TE, Gavra G, Feindel CM, et al. Surgical treatment of active infective endocarditis: a continued challenge. J Thorac Cardiovasc Surg 2007;133:144-9.

79. Kim JB, Ejiofor JI, Yammine M, et al. Are homografts superior to conventional prosthetic valves in the setting of infective endocarditis involving the aortic valve? J Thorac Cardiovasc Surg 2016;151:1239-48.e12482.

80. Fukushima S, Tesar PJ, Pearse B, et al. Long-term clinical outcomes after aortic valve replacement using cryopreserved aortic allograft. J Thorac Cardiovasc Surg 2014;148:65-72.e2.

81. Hussain ST, Shrestha NK, Gordon SM, et al. Residual patient, anatomic, and surgical obstacles in treating active left-sided infective endocarditis. J Thorac Cardiovasc Surg 2014;148:981-8.e4.

82. Grubitzsch H, Schaefer A, Melzer C, et al. Outcome after surgery for prosthetic valve endocarditis and the impact of preoperative treatment. J Thorac Cardiovasc Surg 2014;148:2052-9.

83. Manne MB, Shrestha NK, Lytle BW, et al. Outcomes after surgical treatment of native and prosthetic valve infective endocarditis. Ann Thorac Surg 2012;93:489-93.

84. Moon MR, Miller DC, Moore KA, et al. Treatment of endocarditis with valve replacement: the question of tissue versus mechanical prosthesis. Ann Thorac Surg 2001;71:1164-71.

85. Flameng W, Daenen W, Jashari R, et al. Durability of homografts used to treat complex aortic valve endocarditis. Ann Thorac Surg 2015;99:1234-8.

86. Arabkhani B, Bekkers JA, Andrinopoulou ER, et al. Allografts in aortic position: Insights from a 27-year, single-center prospective study. J Thorac Cardiovasc Surg 2016;152:1572-79.e3.

87. Musci M, Weng Y, Hubler M, et al. Homograft aortic root replacement in native or prosthetic active infective endocarditis: twenty-year single-center experience. J

Thorac Cardiovasc Surg 2010;139:665-73.

88. Yankah AC, Klose H, Petzina R, et al. Surgical management of acute aortic root endocarditis with viable homograft:13year. Eur J Cardiothorac Surg 2002;21:260-7.

89. Perrotta S, Jeppsson A, Frojd V, et al. Surgical Treatment of Aortic Prosthetic Valve Endocarditis: A 20-Year SingleCenter Experience. Ann Thorac Surg 2016;101:1426-32.

90. Nappi F, Spadaccio C, Chello M, et al. The Ross procedure: Underuse or under-comprehension? J Thorac Cardiovasc Surg 2015;149:1463-4.

91. Nappi F, Nenna A, Larobina D, et al. Simulating the ideal geometrical and biomechanical parameters of the pulmonary autograft to prevent failure in the Ross operation. Interact Cardiovasc Thorac Surg 2018;27:269-76.

92. Nappi F, Avtaar Singh SS, Spadaccio C, et al. Ross operation 23 years after surgery: It should not be a "forgotten" option. J Card Surg 2020;35:952-6.

93. Nappi F, Spadaccio C, Al-Attar N, et al. The Ross procedure at the crossroads: lessons from biology: is $\mathrm{Dr}$ Ross's dream concluded? Int J Cardiol 2015;178:37-9

94. Spadaccio C, Montagnani S, Acar C, et al. Introducing bioresorbable scaffolds into the show. A potential adjunct to resuscitate Ross procedure. Int J Cardiol 2015;190:50-2.

95. Nappi F, Fraldi M, Spadaccio C, et al. Biomechanics drive histological wall remodeling of neoaortic root: A mathematical model to study the expression levels of ki 67 , metalloprotease, and apoptosis transition. J Biomed Mater Res A 2016;104:2785-93.

96. Nappi F, Carotenuto AR, Cutolo A et al. Compliance mismatch and compressive wall stresses drive anomalous remodelling of pulmonary trunks reinforced with Dacron grafts. J Mech Behav Biomed Mater 2016;63:287-302.

97. Spadaccio C, Nappi F, Al-Attar N, et al. Old Myths, New Concerns: the Long-Term Effects of Ascending Aorta Replacement with Dacron Grafts. Not All That Glitters Is Gold. J Cardiovasc Transl Res 2016;9:334-42.

Cite this article as: Benedetto U, Spadaccio C, Gentile F, Moon MR, Nappi F. A narrative review of early surgery versus conventional treatment for infective endocarditis: do we have an answer? Ann Transl Med 2020;8(23):1626. doi: 10.21037/atm20-3880 